\title{
DISCRETE-TIME OUTPUT FEEDBACK SLIDING MODE CONTROL FOR UNCERTAIN SYSTEMS
}

Ming-Chang Pai

Department of Automation Engineering, Nan Kai University of Technology, Tsao-Tun, Taiwan, R.O.C., pmc@nkut.edu.tw

Follow this and additional works at: https://jmstt.ntou.edu.tw/journal

Part of the Electrical and Computer Engineering Commons

\section{Recommended Citation}

Pai, Ming-Chang (2008) "DISCRETE-TIME OUTPUT FEEDBACK SLIDING MODE CONTROL FOR UNCERTAIN SYSTEMS," Journal of Marine Science and Technology. Vol. 16: Iss. 4, Article 8.

DOI: 10.51400/2709-6998.2016

Available at: https://jmstt.ntou.edu.tw/journal/vol16/iss4/8

This Research Article is brought to you for free and open access by Journal of Marine Science and Technology. It has been accepted for inclusion in Journal of Marine Science and Technology by an authorized editor of Journal of Marine Science and Technology. 


\title{
DISCRETE-TIME OUTPUT FEEDBACK SLIDING MODE CONTROL FOR UNCERTAIN SYSTEMS
}

\author{
Ming-Chang Pai*
}

Key words: discrete-time output feedback, sliding mode control, uncertain systems, chattering phenomenon.

\begin{abstract}
This paper presents a discrete-time output feedback sliding mode control to stabilize a class of linear uncertain systems in which the state is unavailable and no estimated state is required. The proposed sliding mode controller is derived to guarantee the existence of quasi-sliding mode by using output feedback only and the stability of overall closed-loop system is assured. This scheme ensures the robustness against parametric uncertainties and disturbances. Neither chattering phenomenon will occur nor the knowledge of upper bound of uncertainties is required. Simulation results demonstrate the efficacy of the proposed control methodology.
\end{abstract}

\section{INTRODUCTION}

The theory of sliding mode control (SMC) is often used in controlling of uncertain systems. The main merit of SMC is their fast response, good transient performance, insensitiveness to matching parameter uncertainties and external disturbances $[2,3,9,17]$. In practice, using computers or DSP chips to implement the controller becomes more and more important nowadays, and discrete-time SMC has gained more and more attractive attention recently. Different from continuous-time SMC, the motion of a discrete-time SMC system can approach the switching surface but cannot stay on it in practice. Therefore, only the quasi-sliding mode is ensured $[6,12,15]$.

Several design methods for discrete-time SMC have been proposed in the literature $[1,5-7,12,13,15,16,18,19]$. However, all these papers are always limited to systems with full-state feedback. In practice, full measurement of the state vector is not feasible. Such situations would demand the use of observers or dynamic compensators, which would add to the system complexity. Because the direct output feedback in SMC has a desirable feature as it does not add any additional dynamics and is

Paper submitted 08/09/07; accepted 12/18/07. Author for correspondence: Ming-Chang Pai (e-mail:pmc@nkut.edu.tw).

*Department of Automation Engineering, Nan Kai University of Technology, Tsao-Tun, Taiwan, R.O.C. simpler to implement, several research works are available to deal with SMC design using static output feedback $[4,10,11,14,20]$. Wang and Fan [20], Kwan [10,11] and Edwards et al. [4] have developed output feedback SMC to stabilize a class of uncertain systems. Pai and Sinha [14] developed an output feedback SMC method for time-varying mismatched uncertain systems. However, these control techniques are always limited to continuous-time systems.

In this paper, we extend the idea of Wang and Fan [20] and Kwan [10] from continuous-time output feedback SMC to discrete-time output feedback SMC. A discrete-time sliding mode controller using only output variable is proposed to stabilize uncertain systems robustly. The scheme is very simple in structure and easy to implement because no observer is needed. By using the proposed controller, the stability of system in the quasi-sliding mode is assured under certain conditions. The robustness against parametric uncertainties and disturbances is ensured. Neither chattering phenomenon will occur nor the knowledge of upper bound of uncertainties is required. Furthermore, it can be suitable for uncertain systems with both matched state delays and input delays.

This paper is organized as follows. Section 2 briefly states problem formulation and assumptions. Section 3 provides the proposed discrete-time output feedback SMC scheme. The selection of sliding surface, the design of sliding mode controller, and the stability of system in the quasi-sliding mode have been addressed. Section 4 presents results from numerical simulations. Finally, a conclusion is provided in section 5 .

\section{PROBLEM FORMULATION AND ASSUMPTIONS}

Consider a discrete-time uncertain system represented by:

$$
\begin{gathered}
\bar{x}_{k+1}=(\bar{A}+\Delta \bar{A}) \bar{x}_{k}+(\bar{B}+\Delta \bar{B}) u_{k}+f_{k} \\
y_{k}=\bar{C} \bar{x}_{k}
\end{gathered}
$$

where $\bar{x}_{k} \in R^{n}$ is the state vector, $u_{k} \in R^{m}$ is the control input, $y_{k} \in R^{p}$ is the output, $\bar{A}, \bar{B}$, and $\bar{C}$ are system matrices of appropriate dimensions, $\Delta \bar{A}, \Delta \bar{B}$ and $f_{k}$ represent unknown parametric uncertainties and external disturbances respectively. For completing the description of discrete-time uncertain 
system (1), the following assumptions are assumed to be valid:

Assumption 1. The system $(\bar{A}, \bar{B}, \bar{C})$ is controllable and observable.

Assumption 2. $\operatorname{rank}(\overline{C B})=m$; i.e. $\operatorname{rank}(\bar{B})=m$.

Assumption 3. There exist matrices of appropriate dimension $\hat{D}_{a}, \hat{D}_{b}$ and $\hat{f}_{k}$ such that $\Delta \bar{A}=\bar{B} \hat{D}_{a}, \Delta B=\bar{B} \hat{D}_{b}$ and $f_{k}=\bar{B} \hat{f}_{k}$. These conditions are so-called matching conditions [3].

Using Assumption 3, discrete-time uncertain system (1) can be rewritten as

$$
\begin{gathered}
\bar{x}_{k+1}=\bar{A} \bar{x}_{k}+\bar{B} u_{k}+\bar{B} d_{k} \\
y_{k}=\bar{C} \bar{x}_{k}
\end{gathered}
$$

where the generalized uncertainty $d_{k}$ is constructed as $d_{k}=\hat{D}_{a} \bar{x}_{k}+\hat{D}_{b} u_{k}+\hat{f}_{k}$ and is assumed to be bounded.

The objective of this paper is to develop a discrete-time output feedback sliding mode controller such that discrete-time uncertain system (2) is asymptotically stable even in the presence of parametric uncertainties and external disturbances.

In this paper, the switching function is defined as

$$
S_{k}=G y_{k}
$$

where $G \in R^{m \times p}$ is a constant matrix to be designed.

\section{MAIN RESULTS}

The design of discrete-time SMC consists of two steps: The first step is to design a switching surface such that in the quasi-sliding mode system response acts like the desired dynamics. The second step is to design the control law in order that quasi-sliding mode is reached and sustained for all time.

\section{Design of switching surface}

Define a state variable transformation

$$
x_{k}=H \bar{x}_{k}
$$

where $H \in R^{n \times n}$ is an orthogonal transformation matrix such that

$$
H \bar{B}=\left[\begin{array}{c}
0 \\
B_{2}
\end{array}\right]=B
$$

where $B_{2} \in R^{m \times m}$ is a nonsingular matrix.

Using (4), equations (2.a) and (2.b) can be rewritten as

$$
\begin{gathered}
x_{k+1}=A x_{k}+B u_{k}+B d_{k} \\
y_{k}=C x_{k}
\end{gathered}
$$

where $A=H \bar{A} H^{-1}$ and $C=\bar{C} H^{-1}$.
From (5), the first $(n-m)$ rows of $B$ are zero. Therefore, the state vector $x_{k}$ is partitioned as follows:

$$
x_{k}=\left[\begin{array}{c}
x_{1 k} \\
x_{2 k}
\end{array}\right]
$$

where $x_{1 k} \in R^{n-m}$ and $x_{2 k} \in R^{m}$. Then, the dynamics of $x_{1 k}$ can be written from (6.a) as

$$
x_{1 k+1}=A_{11} x_{1 k}+A_{12} x_{2 k}
$$

where $A_{11}$ and $A_{12}$ are parts of the matrix $A$ corresponding to the partition (7). Similarly, partitioning the matrix $C$ according to (7), output equation (6.b) can then be rewritten as

$$
y_{k}=C_{1} x_{1 k}+C_{2} x_{2 k}
$$

where $C_{1} \in R^{p \times(n-m)}$ and $C_{2} \in R^{p \times m}$.

Assuming that $G C_{2}$ is nonsingular, equations (3) and (9) yield

$$
x_{2 k}=\left(G C_{2}\right)^{-1}\left(-G C_{1} x_{1 k}+S_{k}\right)
$$

Substituting (10) into (8)

$$
x_{1 k+1}=\left[A_{11}-A_{12}\left(G C_{2}\right)^{-1} G C_{1}\right] x_{1 k}+A_{12}\left(G C_{2}\right)^{-1} S_{k}
$$

Thus, discrete-time uncertain system (6) in the quasi-sliding mode can be reduced to the following n-m dimensional form

$$
x_{1 k+1}=\left(A_{11}-A_{12} K C_{1}\right) x_{1 k}
$$

where $K=\left(G C_{2}\right)^{-1} G$.

or

$$
x_{1 k+1}=A_{m} x_{1 k}
$$

where $A_{m}=A_{11}-A_{12} K C_{1}$.

Equation (12) can be considered as a linear output feedback problem. The matrix $G$ can be selected to satisfy Lemma 1 of [20], i.e.

$$
\operatorname{rank}\left(C_{2} K-I\right) \leq p-m
$$

\section{Design of Discrete-Time Sliding Mode Controller}

After designing the switching surface, the next phase is to design the control law such that quasi-sliding mode is reached and stayed thereafter. Before design the controllers, we first give a lemma proposed by Sarpturk [15].

\section{Lemma 1}

A necessary and sufficient condition for a discrete-time SMC to assure both sliding motion and convergence onto the hyperplane is

$$
\left\|S_{k+1}\right\|<\left\|S_{k}\right\|
$$

Condition (14) can be further decomposed into the following two inequalities: 


$$
\begin{aligned}
& S_{k}^{T}\left[S_{k+1}-S_{k}\right]<0 \\
& S_{k}^{T}\left[S_{k+1}+S_{k}\right]>0
\end{aligned}
$$

where (15) and (16) are called sliding condition and convergence condition, respectively.

\section{Lemma 2}

Consider the equivalent reduced-order system (12.b). Let $\left\|\lambda_{m}\right\|<1$ be the maximum real part of the eigenvalues of $A_{m}$.

Then, $\left\|x_{1 k}\right\|$ is bounded by $w_{k}$ for all $k$, where $w_{k}$ is the solution of

$$
w_{k+1}=\lambda_{w} w_{0}+\rho\left(\left\|A_{12}\left(G C_{2}\right)^{-1} S_{k}\right\|\right)
$$

$, 0<\lambda_{m}<\lambda_{w}<1, \rho=\|N\|\left\|N^{-1}\right\|, w_{0}>\rho\left\|x_{10}\right\|>0$ and $N$ is a transformation matrix.

Proof:

Since matrices $K$ and $G$ can be designed such that $A_{m}$ is stable, all the eigenvalues of $A_{m}$ lie inside the unit circle of the z-plane, and can be expressed as $\lambda_{1}, \lambda_{2}, \cdots, \lambda_{n-m}$. The solution of (11) can be obtained as

$$
x_{1 k}=N J^{k} N^{-1} x_{10}+N\left(\sum_{i=0}^{k-1} J^{i} N^{-1}\left[A_{12}\left(G C_{2}\right)^{-1} S_{k-i-1}\right]\right)
$$

where $J=\operatorname{diag}\left(\lambda_{1}, \lambda_{2}, \cdots, \lambda_{n-m}\right)$ and $N$ is a transformation matrix. Then, from (18)

$$
\begin{gathered}
\left\|x_{1 k}\right\| \leq \rho\left\|J^{k}\right\|\left\|x_{10}\right\|+\rho\left(\sum_{i=0}^{k-1}\left\|J^{i}\right\|\left\|A_{12}\left(G C_{2}\right)^{-1} S_{k-i-1}\right\|\right) \\
\quad \leq \rho\left\|\lambda_{m}^{k}\right\|\left\|x_{10}\right\|+\rho\left(\sum_{i=0}^{k-1}\left\|\lambda_{m}^{i}\right\|\left\|A_{12}\left(G C_{2}\right)^{-1} S_{k-i-1}\right\|\right)
\end{gathered}
$$

where $\rho=\|N\|\left\|N^{-1}\right\|$.

The solution of (17) is given by

$$
w_{k} \leq\left\|\lambda_{w}^{k}\right\|\left\|w_{0}\right\|+\rho\left(\sum_{i=0}^{k-1}\left\|\lambda_{w}^{i}\right\|\left\|A_{12}\left(G C_{2}\right)^{-1} S_{k-i-1}\right\|\right)
$$

Comparing the right-hand sides of (19) and (20), and noting the fact that $0<\lambda_{m}<\lambda_{w}<1$, it yields

$$
w_{k} \geq\left\|x_{1 k}\right\|
$$

for all $k$. The proof is completed.

In the sequel, we consider the control law for discrete-time uncertain system (6) as

$$
u_{k}=-\alpha(G C B)^{-1} S_{k}-d_{k-1}
$$

where the generalized disturbance $d_{k}$ defined in (2) can be estimated through the following relation

$$
d_{k-1}=(G C B)^{-1}\left(G C x_{k}-G C A x_{k-1}-G C B u_{k-1}\right)
$$

and $\alpha>0$ will be designed later. Since $\operatorname{rank}(C B)=m$, $(G C B)^{-1}$ exists.

\section{Theorem 1}

Consider the discrete-time uncertain system (6) with the proposed control law (22) and switching function (3). If there exist matrices $K$ and $G$ such that eigenvalues of the matrix $A_{11}-A_{12} K C_{1}$ are within the unit circle in the Z-plane, then

(a) the quasi-sliding mode condition $\left\|S_{k+1}\right\|<\left\|S_{k}\right\|$ will be satisfied outside the region $\mathrm{A}$, where the region $\mathrm{A}$ is defined as $\Omega_{A}=\left\{S_{k}:\left\|S_{k}\right\| \leq \max _{r_{1}<\alpha<\left(2-r_{1}\right)}\left[\begin{array}{ll}\frac{\eta_{k}}{\alpha-r_{1}} & \frac{\eta_{k}}{2-\alpha-r_{1}}\end{array}\right]\right\}$ and

$$
\begin{aligned}
& r_{1}=\|G C A-G C\|\left\|\left(G C_{2}\right)^{-1}\right\| \quad \text { and } \\
& \eta_{k}=\|G C A-G C\|\left\|H_{1}\right\|\left\|w_{k}\right\|+\varepsilon_{k} \quad \text { with } \\
& H_{1}=\left[\begin{array}{c}
I_{n-m} \\
-\left(G C_{2}\right)^{-1} G C_{1}
\end{array}\right], \quad w_{k} \quad \text { satisfying (17) and } \\
& \left\|G C B\left(d_{k}-d_{k-1}\right)\right\| \leq \varepsilon_{k} \text {. }
\end{aligned}
$$

(b) the quasi-sliding mode of discrete-time uncertain system (6) is stable.

\section{Proof :}

First, we prove that $\left\|S_{k+1}\right\|<\left\|S_{k}\right\|$ is satisfied. For this, the proof includes two parts.

Part I. (Sliding condition). From (3), (6) and (22), the difference between $S_{k+1}$ and $S_{k}$ can be expressed as

$$
\begin{gathered}
S_{k+1}-S_{k}=G C x_{k+1}-G C x_{k} \\
=G C A x_{k}+G C B u_{k}+G C B d_{k}-G C x_{k} \\
=(G C A-G C) x_{k}-\alpha S_{k}+G C B\left(d_{k}-d_{k-1}\right)
\end{gathered}
$$

Pre-multiplying (24) by $S_{k}^{T}$

$$
\begin{gathered}
S_{k}^{T}\left[S_{k+1}-S_{k}\right]=-\alpha\left\|S_{k}\right\|^{2}+S_{k}^{T}\left[(G C A-G C) x_{k}\right. \\
\left.+G C B\left(d_{k}-d_{k-1}\right)\right]
\end{gathered}
$$

$$
\begin{gathered}
<-\alpha\left\|S_{k}\right\|^{2}+\left\|S_{k}\right\|\left[\|G C A-G C\|\left\|x_{k}\right\|+\left\|G C B\left(d_{k}-d_{k-1}\right)\right\|\right] \\
<-\alpha\left\|S_{k}\right\|^{2}+\left\|S_{k}\right\|\left[\|G C A-G C\|\left\|x_{k}\right\|+\varepsilon_{k}\right]
\end{gathered}
$$

However, the state vector $x_{k}$ in (25) is not available. But, the upper bound on its norm can be estimated as follows. From (10), the state vector $x_{k}$ can be rewritten as 


$$
x_{k}=\left[\begin{array}{c}
x_{1 k} \\
x_{2 k}
\end{array}\right]=H_{1} x_{1 k}+\left[\begin{array}{c}
0 \\
\left(G C_{2}\right)^{-1} S_{k}
\end{array}\right]
$$

where $H_{1}=\left[\begin{array}{c}I_{n-m} \\ -\left(G C_{2}\right)^{-1} G C_{1}\end{array}\right]$.

Using (26) and (21), the upper bound of the state vector $\left\|x_{k}\right\|$ can be expressed as

$$
\begin{gathered}
\left\|x_{k}\right\| \leq\left\|H_{1}\right\|\left\|x_{1 k}\right\|+\left\|\left(G C_{2}\right)^{-1}\right\|\left\|S_{k}\right\| \\
\leq\left\|H_{1}\right\|\left\|w_{k}\right\|+\left\|\left(G C_{2}\right)^{-1}\right\|\left\|S_{k}\right\|
\end{gathered}
$$

Substituting (27) into (25)

$$
\begin{gathered}
S_{k}^{T}\left[S_{k+1}-S_{k}\right]<-\alpha\left\|S_{k}\right\|^{2}+\left\|S_{k}\right\|\left[\|G C A-G C\|\left\|H_{1}\right\|\left\|w_{k}\right\|\right. \\
\left.+\|G C A-G C\|\left\|\left(G C_{2}\right)^{-1}\right\|\left\|S_{k}\right\|+\varepsilon_{k}\right] \\
<-\left(\alpha-r_{1}\right)\left\|S_{k}\right\|\left(\left\|S_{k}\right\|-\frac{\eta_{k}}{\alpha-r_{1}}\right)
\end{gathered}
$$

where

$$
r_{1}=\|G C A-G C\|\left\|\left(G C_{2}\right)^{-1}\right\|
$$

$\eta_{k}=\|G C A-G C\|\left\|H_{1}\right\|\left\|w_{k}\right\|+\varepsilon_{k}$.

The sliding condition (15) will be satisfied if $\left\|S_{k}\right\| \geq \frac{\eta_{k}}{\alpha-r_{1}}$ and $\alpha-r_{1}>0$. Therefore, with a known bound of initial state $w_{0}$, a stable $A_{m},\left\|S_{k}\right\| \geq \frac{\eta_{k}}{\alpha-r_{1}}$ and $\alpha-r_{1}>0$, the sliding condition $S_{k}^{T}\left[S_{k+1}-S_{k}\right]<0$ is achieved.

Part II. (Convergence condition). From (3), (6) and (22), the sum between $S_{k+1}$ and $S_{k}$ can be expressed as

$$
\begin{gathered}
S_{k+1}+S_{k}=G C A x_{k}+G C B u_{k}+G C B d_{k}+S_{k} \\
=(G C A-G C) x_{k}-\alpha S_{k}+G C B\left(d_{k}-d_{k-1}\right)+2 S_{k}
\end{gathered}
$$

Pre-multiplying (28) by $S_{k}^{T}$ and using (27)

$$
\begin{gathered}
S_{k}^{T}\left[S_{k+1}+S_{k}\right]=(2-\alpha)\left\|S_{k}\right\|^{2}+S_{k}^{T}\left[(G C A-G C) x_{k}\right. \\
\left.+G C B\left(d_{k}-d_{k-1}\right)\right] \\
>(2-\alpha)\left\|S_{k}\right\|^{2}-\|S\|\left[\|G C A-G C\|\left\|x_{k}\right\|+\varepsilon_{k}\right] \\
=(2-\alpha)\left\|S_{k}\right\|^{2}-\left\|S_{k}\right\|\left[r_{1}\left\|S_{k}\right\|+\eta_{k}\right] \\
=\left(2-\alpha-r_{1}\right)\left\|S_{k}\right\|\left[\left\|S_{k}\right\|-\frac{\eta_{k}}{\left(2-\alpha-r_{1}\right)}\right]
\end{gathered}
$$

If $\left\|S_{k}\right\| \geq \frac{\eta_{k}}{2-\alpha-r_{1}} \quad$ and $\quad\left(2-\alpha-r_{1}\right)>0 \quad, \quad$ then $S_{k}^{T}\left[S_{k+1}+S_{k}\right]>0$, which implies that the convergence condition is achieved. From Part I, Part II and Lemma 1, if $S_{k} \geq \max _{r_{1}<\alpha<\left(2-r_{1}\right)}\left\{\frac{\eta_{k}}{\alpha-r_{1}}, \frac{\eta_{k}}{2-\alpha-r_{1}}\right\} \quad, \quad$ it concludes $\left\|S_{k+1}\right\|<\left\|S_{k}\right\|$, which indicates that switching function $S_{k}$ is decreasing outside $\Omega_{A}$.

Once the quasi-sliding mode condition $\left\|S_{k+1}\right\|<\left\|S_{k}\right\|$ is satisfied, the system state trajectories will approach the switching surface in finite time. From (12), it shows that the dynamical equation of the quasi-sliding mode. Since matrices $K$ and $G$ can be designed such that eigenvalues of the matrix $A_{11}-A_{12} K C_{1}$ are within the unit circle in the Z-plane, it is obvious that the quasi-sliding mode of discrete-time uncertain system (6) is stable. The proof is completed.

It is noted from (22) that there is no switching action in the proposed controllers, which means that chattering phenomenon will never happen. Also, the other advantage of (22) is that upper bound of the uncertainty $d_{k}$ needs not to be known beforehand when the controller is implemented. Hence, it will increase the applicability of the proposed control scheme.

\section{Remark 1}

In general, it is usually desired to have a minimum bound of $\Omega_{A}$ in order to increase the accuracy of control if the uncertainty $d_{k}$ exists. Hence, the designed parameter $\alpha$ in the control law (22) will be selected such that that the least upper bound of $\min _{r_{1}<\alpha<\left(2-r_{1}\right)}\left\|S_{k}\right\|=\min \left\{\max _{r_{1}<\alpha<\left(2-r_{1}\right)}\left\{\frac{\eta_{k}}{\alpha-r_{1}}, \frac{\eta_{k}}{2-\alpha-r_{1}}\right\}\right\} \quad$ is achieved.

\section{Remark 2}

From remark 1, it shows that the least upper bound of $\min _{r_{1}<\alpha<\left(2-r_{1}\right)}\left\|S_{k}\right\|=\min \left\{\max _{r_{1}<\alpha<\left(2-r_{1}\right)}\left\{\frac{\eta_{k}}{\alpha-r_{1}}, \frac{\eta_{k}}{2-\alpha-r_{1}}\right\}\right\} \quad$ will increase the accuracy of control, which implies the $\eta_{k}$ will affect the accuracy of control. From Theorem 1, it shows the $\eta_{k}$ is related to the generalized uncertainty difference. It is obvious that the smaller generalized uncertainty difference will increase the more accuracy of control.

\section{ILLUSTRATIVE EXAMPLES}

To illustrate the utilization of the proposed approach, we consider an aircraft model which is used in $[10,11,20]$. The state-space model of the aircraft is given by 


$$
\begin{gathered}
{\left[\begin{array}{c}
\dot{\varphi} \\
\dot{q} \\
\dot{\delta}_{e}
\end{array}\right]=\left[\begin{array}{ccc}
-0.277 & 1 & -0.0002 \\
-17.1 & -0.178 & -12.2 \\
0 & 0 & -6.67
\end{array}\right]\left[\begin{array}{c}
\varphi \\
q \\
\delta_{e}
\end{array}\right]+\left[\begin{array}{c}
0 \\
0 \\
6.67
\end{array}\right] u} \\
y=\left[\begin{array}{l}
y_{1} \\
y_{2}
\end{array}\right]=\left[\begin{array}{lll}
0 & 1 & 0 \\
0 & 0 & 1
\end{array}\right]\left[\begin{array}{c}
\varphi \\
q \\
\delta_{e}
\end{array}\right]
\end{gathered}
$$

where $\varphi$ is the attack angle, $q$ is the pitch rate, $\delta_{e}$ is the elevator angle, $u$ is the command to the elevator, and $y$ is the measurement vector. The parametric uncertainty and disturbance are respectively assumed to be

$$
\begin{gathered}
\hat{D}_{a}=0.1[\sin (t)+\cos (2 t) \quad \sin (3 t) \cos (t) \quad-1+\sin (2 t) \cos (3 t)] \\
\hat{f}=\left[\begin{array}{lll}
0 & 0 & 0.5
\end{array}\right]
\end{gathered}
$$

The discrete-time transformed system (2) for each sampling time can be easily obtained using the Matlab program function c2d [8] with $T_{s}=0.001$ second and given as

$$
\begin{gathered}
\bar{x}_{k+1}=\left[\begin{array}{ccc}
0.9997 & 0.001 & 0 \\
-0.0171 & 0.9998 & -0.0122 \\
0 & 0 & 0.9934
\end{array}\right] \bar{x}_{k}+\left[\begin{array}{c}
0 \\
0 \\
0.0066
\end{array}\right] u_{k} \\
+\left[\begin{array}{c}
0 \\
0 \\
0.0066
\end{array}\right] d_{k}
\end{gathered}
$$

Since the matrix $\bar{B}$ is of the form in (5), we need not transform the system. Define $x_{1 k}=\left[\begin{array}{ll}\varphi_{k} & q_{k}\end{array}\right]^{T}$ and $x_{2 k}=\delta_{e k}$, then

$$
\begin{gathered}
A_{11}=\left[\begin{array}{cc}
0.9997 & 0.001 \\
-0.0171 & 0.9998
\end{array}\right], A_{12}=\left[\begin{array}{c}
0 \\
-0.0122
\end{array}\right], C_{1}=\left[\begin{array}{ll}
0 & 1 \\
0 & 0
\end{array}\right], \\
C_{2}=\left[\begin{array}{l}
0 \\
1
\end{array}\right] .
\end{gathered}
$$

According to (13), we choose $G=[-0.46351]$ to place the eigenvalues of the reduced-order system (12) at $0.9969 \pm 0.0031 i$. The initial state vector is chosen as $x_{0}=\left[\begin{array}{lll}2 & 0 & 0\end{array}\right]^{T}$. Also, $\lambda_{w}, \rho$ and $w_{0}$ in (17) are taken to be $0.998,5.7333$ and 11.5 , respectively. Then, the controller (22) with $\alpha=1$ can be designed as

$$
u_{k}=-150 S_{k}-d_{k-1}
$$

where $S_{k}$ and $d_{k-1}$ are given in (3) and (23), respectively.

With the designed parameter setting and initial condition $y_{0}=\left[\begin{array}{ll}2 & 0\end{array}\right]^{T}$, the results of simulation are shown in Figs. 1-4. Fig. 1 shows that output trajectories of the system, which con-

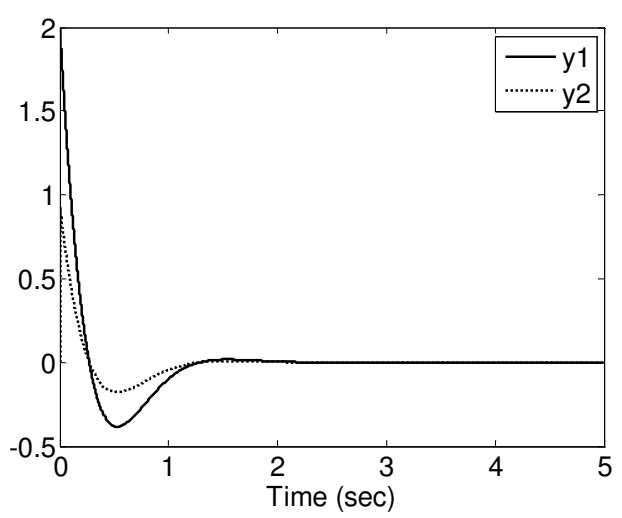

Fig. 1. Output trajectories $q_{k}$ and $\delta_{e k}$.

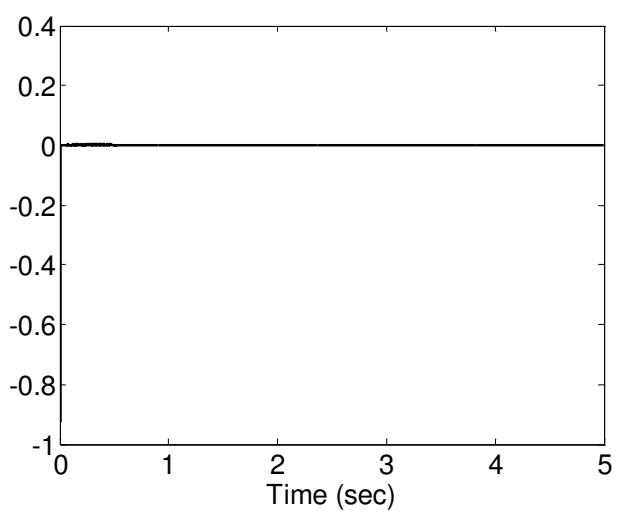

Fig. 2. Switching surface variable $S_{k}$.

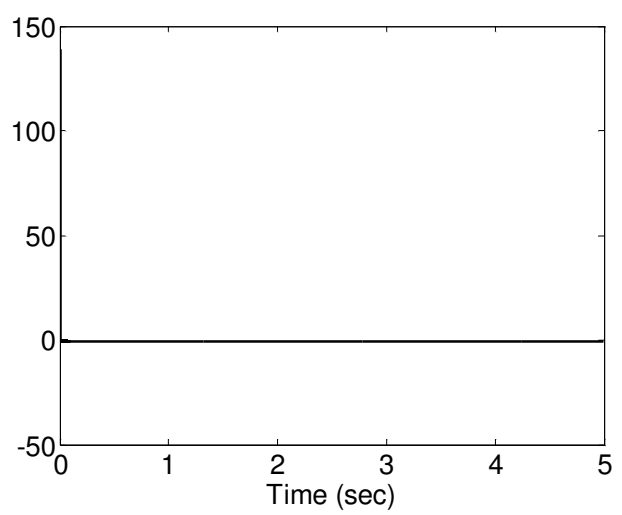

Fig. 3. Control input $u_{k}$.

firm the stability and robustness of the closed-loop system to parametric uncertainties and disturbances. Fig. 2 shows the switching surface variable. Fig. 3 shows that the control input with reasonable magnitudes. It can be seen that the chattering phenomenon is eliminated. Fig. 4 shows the performance of $w_{k}$ and $\left\|x_{1 k}\right\|$. It can be seen that the $\left\|x_{1 k}\right\|$ is smaller than $w_{k}$ for all $k$.

\section{CONCLUSION}

In this paper, a discrete-time output feedback SMC scheme 


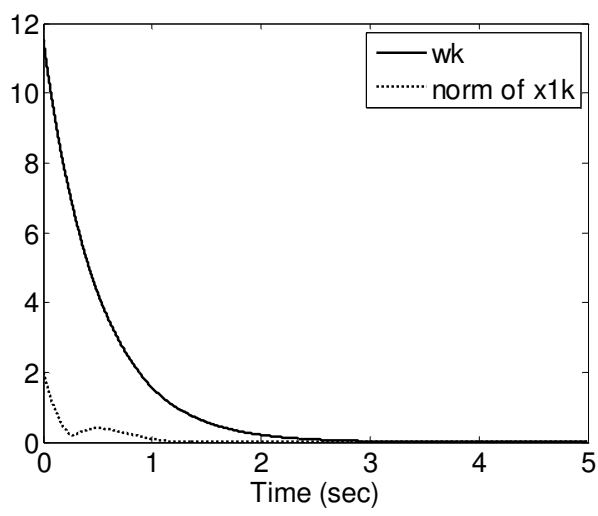

Fig. 4. Performance of $w_{k}$ and $\left\|x_{1 k}\right\|$.

has been proposed to stabilize a class of uncertain systems. The design technique is simple and efficient. The proposed controller use only output variable and no observer is required. The selection of switching surface and the existence of the quasi-sliding mode are two important issues, which have been addressed. It has been shown that the stability of the closed-loop system is guaranteed. Neither chattering phenomenon will occur nor the knowledge of upper bound of uncertainties is required beforehand. Furthermore, it can be suitable for uncertain systems with both matched state delays and input delays. Simulation studies have confirmed the validity of this proposed control system.

\section{REFERENCES}

1. Abidi, K., Xu, J.-X., and Xinghuo, Y., "On the discrete-time integral sliding-mode control," IEEE Transactions on Automatic Control, Vol. 52, No. 4, pp.709-705 (2007).

2. DeCarlo, R. S., Zak, S., and Mathews, G., "Variable structure control of nonlinear multivariable systems: a tutorial," Proceedings of IEEE, Vol. 76, pp. 212-232 (1988).

3. Drazenovic', B., "The invariance condition in variable structure systems," Automatica, Vol. 5, pp. 287-295 (1969).

4. Edwards, C., Spurgeon, S. K. and Hebden, R. G., "On the design of sliding mode output feedback controllers", International Journal of
Control, Vol. 76, No. 9/10, pp. 893-905 (2003).

5. Furuta, K., "Sliding mode control of a discrete system," System \& Control Letters, Vol. 14, pp. 145-152 (1990).

6. Gao, W. B., Hung, Y., and Homaifa, A., "Discrete-time variable structure control systems," IEEE Transactions on Industrial Electronics, Vol. 42, No. 2, pp. 117-122 (1995).

7. Garcia, J. P. F., Ribeiro, J. M. S., Silva, J. J. F., and Marins, E. S., "Continuous-time and discrete-time sliding mode control accomplished using a computer," IEE Proceedings-Control Theory and Applications, Vol. 152, No. 2, pp. 220-228 (2005).

8. Grace, A., Control Toolbox for Use with Matlab, The Math Works Natick, MA., (1993).

9. Hung, J. Y., Gao, W., and Hung, J. C., "Variable structure control: a survey," IEEE Transactions on Industrial Electronics, Vol. 40, pp. 2-22 (1993).

10. Kwan, C. M., “On variable structure output feedback controllers,” IEEE Transactions on Automatic Control, Vol. 41, No. 11, pp.1691-1693 (1996).

11. Kwan, C. M., "Further results on variable structure output feedback controllers", IEEE Transactions on Automatic Control, Vol. 46, No. 9 , pp.1505-1508 (2001).

12. Milosavljevic, D., "General conditions for the existence of a quasi-sliding mode on the switching hyperplane in discrete variable structure systems," Automation and Remote Control, Vol. 46, pp. 307-314 (1985).

13. Monsees, G. and Scherpen J. M. A., "Adaptive switching gain for a discrete-time sliding mode controller," International Journal of Control, Vol 75, No. 4, pp.242-251 (2002).

14. Pai, M. C. and Sinha, A., "Sliding mode output feedback control of time-varying mismatched uncertain systems," IEEE International Conference on Systems, Man and Cybernetics, pp.1355-1360 (2006).

15. Sarpturk, S. Z., Istefanopulos, Y., and Kaynak, O., "On the stability of discrete-time sliding mode control systems," IEEE Transactions on Automatic Control, Vol. 32, No. 10, pp. 930-937 (1987).

16. Su, W. C., Drakunov, S. V., and Özgüner, Ü., “An O $\left(T^{2}\right)$ boundary layer in sliding mode for sampled-data system," IEEE Transactions on Automatic Control, Vol. 45, No. 3, pp. 482-485 (2000).

17. Utkin, V. I., "Variable structure systems with sliding modes," IEEE Transactions on Automatic Control, Vol. 22, No. 2, pp.212-222 (1977).

18. Young, K. D., Utkin, V. I., and Özgüner, Ü., “A control engineer's guide to sliding mode control," IEEE Transactions on Control System Technology, Vol. 7, No. 3, pp. 328-342 (1999).

19. Yu, W.-C. and Wang, G.-J., "Discrete sliding mode controller design based on the LQR suboptimal approach with application on AC servo motor," Journal of the Chinese Institute of Engineers, Vol. 29, No. 5, pp. 873-882 (2006)

20. Wang, W-J. and Fan, Y-T., "New output feedback design in variable structure systems," Journal of Guidance, Control, and Dynamics, Vol. 17, No. 2, pp. 337-340 (1994). 